\section{Trabalho, violência e morte em Campinas, São Paulo, Brasil}

\author{
Work, violence and death in Campinas, \\ São Paulo, Brazil
}

\author{
1 Pós-Graduação em Ciências \\ da Saúde, Mestrado em Saúde \\ Coletiva, Universidade \\ do Vale do Rio dos Sinos, \\ São Leopoldo, Brasil. \\ 2 Departamento de Saúde \\ Pública, Faculdade de \\ Medicina de Botucatu, \\ Universidade Estadual \\ Paulista, Botucatu, Brasil. \\ 3 Departamento de Medicina \\ Preventiva e Social, \\ Universidade Estadual de \\ Campinas, Campinas, Brasil. \\ Correspondência \\ Élida Azevedo Hennington \\ Pós-Graduação em Ciências \\ da Saúde, Mestrado em Saúde \\ Coletiva, Universidade \\ do Vale do Rio dos Sinos. \\ C. P. 275, São Leopoldo, RS \\ 93022-000, Brasil. \\ henningt@bios.unisinos.br
}

\begin{abstract}
In this epidemiological study, deaths resulting from external causes in 1999 and 2000 among males (age 15-64 years) in Campinas, São Paulo State were analyzed through interviews with their relatives. We attempted to correlate this incidence with individual occupational history, allowing the characterization of these events as work-related injuries. The proportional death rate due to work-related injuries was estimated at $27 \%$ in this group. None of the death certificates we analyzed had "yes" specified in the appropriate work-related injury field. Based on these results, official data from the Brazilian Ministry of Labor on the number of deaths resulting from work-related injuries in this period in the State of São Paulo is underestimated by 83.4\%. The vast majority of fatal work-related injuries were homicides and traffic accidents, reflecting an increase in violence in this Brazilian city.
\end{abstract}

Occupational Accidents; Mortality; Violence
Élida Azevedo Hennington 1

Ricardo Cordeiro 2

Djalma de Carvalho Moreira Filho 3

\section{Introdução}

Os acidentes do trabalho (AT) são notoriamente subnotificados no Brasil 1,2,3,4,5. Contribui para esta subnotificação o fato de muitos acidentes de trabalho fatais não serem reconhecidos como relacionados ao trabalho, aparecendo nas estatísticas oficiais como homicídios comuns e acidentes em geral. Isto justifica a necessidade do entendimento e dimensionamento da relação entre a mortalidade por causas externas e os acidentes de trabalho como elemento necessário para a formulação de políticas públicas para a prevenção destes eventos.

Dois fatores concorrem para a subnotificação de acidentes de trabalho no Brasil. Por um lado, não existe um sistema único que centralize as informações sobre AT no país. O banco de dados mais abrangente, gerenciado pelo $\mathrm{Mi}$ nistério da Previdência e Assistência Social (MPAS), subnotifica em $80 \%$ os acidentes ocupacionais ocorridos entre trabalhadores protegidos pela legislação trabalhista 6 . Por outro lado, além de ineficientes, os sistemas de informações ignoram os acidentes ocorridos no mercado informal da economia brasileira, que nos dias de hoje engloba mais de $50 \%$ dos trabalhadores no Brasil 7. Ainda assim, desde 1970, quando começam os registros sistemáticos em âmbito nacional, mais de 30 milhões de acidentes de trabalho foram notificados no país, provocando mais de 100 mil óbitos absolutamente 
evitáveis entre brasileiros jovens e produtivos 8 . Apenas no ano 2000 foram notificados, dentre os trabalhadores segurados, 343.996 acidentes de trabalho, dos quais 14.999 geraram incapacidade permanente e 3.094 resultaram em óbito 8 .

O Município de Campinas, local da realização desta pesquisa, encontra-se situado na região sudeste do Estado de São Paulo, distando cerca de $100 \mathrm{~km}$ da capital. Possuía no ano 2000 uma população de 969.396 habitantes 9 . A cidade, considerada um importante pólo de desenvolvimento industrial de alta tecnologia, constitui o núcleo da terceira maior concentração industrial do Brasil, com indicadores econômicos e de condições de vida satisfatórios; no entanto, além de características de riqueza e desenvolvimento, o município reflete o quadro geral das grandes cidades brasileiras, apresentando graves problemas sociais, como o acentuado crescimento da violência e do desemprego.

Acompanhando o que ocorreu nos grandes centros urbanos brasileiros, a mortalidade por causas externas (homicídios, acidentes, suicídios) em Campinas apresentou tendência crescente a partir dos anos 80. Em 1991, os homicídios ultrapassaram os acidentes de transporte como principal causa de morte violenta, tornando-se a seguir a segunda principal causa de óbito no município em números absolutos, atrás somente das doenças isquêmicas do coração.

Os homicídios atingem sobretudo a faixa etária de 15 a 34 anos, respondendo em Campinas por cerca de $61 \%$ de todas as mortes entre homens, sendo provocados especialmente por armas de fogo. Entre 1999 e 2001, a mortalidade por homicídio na faixa etária de 15 a 24 anos foi de 247,1 óbitos por 100 mil habitantes entre os homens e de 14,3 óbitos por $100 \mathrm{mil}$ habitantes entre as mulheres 10. A incidência de homicídios em Campinas assemelha-se à de regiões metropolitanas brasileiras como as do Rio de Janeiro 11 e de São Paulo 12, e são até mais de cem vezes superiores às observadas em países como Japão e França.

A pequena validade e a parcialidade das informações oficiais sobre AT mencionada anteriormente prejudicam sobremaneira sua quantificação no país. Além disso, existe grande dificuldade em identificar homicídios entre acidentes ocupacionais fatais ocorridos. Na tentativa de superar este problema, análises baseadas unicamente em Declarações de Óbito (DO), infelizmente, são de pouca utilidade. Isto ocorre porque nestas o campo Acidente de Trabalho raramente é preenchido 13,14 , inviabilizando a investigação e caracterização do óbito como decorrente de AT.

Entretanto, estudos recentes sobre AT apontam o crescimento da violência nas grandes cidades e, conseqüentemente, a maior interação deste fenômeno com o indivíduo trabalhador como uma das questões mais significativas na conformação do perfil de mortalidade de trabalhadores brasileiros nos últimos anos 14,15,16.

Assim sendo, torna-se relevante a investigação da mortalidade ocupacional em nosso meio, cuja gravidade é apenas tangenciada pelas estatísticas oficiais. Face à magnitude da ocorrência de acidentes de trabalho no país, o constante aumento da incidência de homicídios nas últimas duas décadas nos grandes centros urbanos, bem como a precariedade de informação sobre esses eventos, este estudo buscou identificar a participação dos acidentes do trabalho entre os óbitos decorrentes de causas externas ocorridos na população masculina em idade produtiva da Cidade de Campinas, como contribuição ao entendimento do quadro geral brasileiro.

\section{Método}

Foram analisadas causas de óbitos de indivíduos do sexo masculino, falecidos com idade entre 15 e 64 anos, residentes na cidade de Campinas, ocorridos entre junho de 1999 a maio de 2000, por intermédio de suas histórias ocupacionais, obtidas de familiares ou amigos dos falecidos.

A Prefeitura Municipal de Campinas rotineiramente recebe de múltiplas fontes a totalidade das DO de falecidos moradores do município. Estas são revisadas, complementadas e corrigidas quando necessário (à luz de informações obtidas em hospitais, no Serviço de Verificação de Óbitos e no Instituto Médico Legal da cidade), reclassificando-se as causas básicas de óbito de acordo com as regras da $10 \underline{a} R e-$ visão da Classificação Internacional de Doenças (CID-10) 17. A partir deste cadastro, foram selecionadas as DO por causas externas, isto é, aquelas DO cuja causa básica classificava-se, após revisão, dentro do Capítulo XX da CID-10. Finalmente, dentre estes óbitos por causas externas, selecionaram-se aqueles referentes a homens entre 15 e 64 anos, sendo amostrado aleatoriamente um terço deste subconjunto, mês a mês no período estudado. 
Valendo-se da informação contida no campo Residência Habitual do Falecido, na Parte II da DO, a família do morador falecido era localizada. Após serem informados sobre os objetivos do estudo, e concordarem em dele participar, familiares e/ou amigos do falecido foram entrevistados. Nas entrevistas, obteve-se a história de trabalho recente do falecido, bem como as circunstâncias relacionadas ao óbito. $\mathrm{O}$ instrumento usado foi um questionário semiestruturado que incluía informações sócio-demográficas sobre o indivíduo falecido, enfocando o histórico e a situação ocupacional no momento do óbito, incluindo características acerca da inserção do indivíduo no mercado de trabalho, além das circunstâncias que envolveram a morte e informações pormenorizadas do evento. As entrevistas permitiram obter dados adicionais e essenciais para a investigação, além de possibilitar retificações das DO, enriquecendo a posterior análise do material. A caracterização de parte dos óbitos analisados como relacionados ao trabalho foi possível em razão dessas informações.

Neste estudo, definiu-se "trabalhador ativo" como o indivíduo que tenha realizado algum tipo de atividade econômica remunerada em dinheiro durante os trinta dias que precederam sua morte, sendo considerado "desempregado" o indivíduo que nos trinta dias que precederam sua morte tomou alguma iniciativa para procurar trabalho remunerado, não o encontrando. Definiu-se "trabalhador informal" como aquele que trabalhou sem contrato formal de trabalho nos trinta dias que precederam sua morte.

\section{Resultados}

No período estudado ocorreram 664 óbitos por causas externas dentre a população masculina de 15 a 64 anos de idade residente no Município de Campinas. Desta população, a cada mês, foram aleatoriamente amostrados $1 / 3$ dos indivíduos, o que resultou em 235 óbitos. Com esta amostra, foi possível a realização de 159 entrevistas com familiares ou amigos do falecido, correspondendo a $67,7 \%$ dos óbitos inicialmente amostrados. As perdas deveram-se à não-localização de familiares decorrente de: incorreções do campo Endereço Habitual do Falecido (13,2\%), mudanças de endereço da família entre o falecimento e a visita domiciliar $(6,8 \%)$, família ausente do endereço em repetidas visitas $(5,1 \%)$, recusas $(3,0 \%)$ e outros motivos $(4,3 \%)$.

Em relação aos entrevistados, 81,4\% tinham algum grau de parentesco com o falecido; $27,8 \%$ eram as mães das vítimas, donas de casa, na faixa etária de 40 a 59 anos, com o primeiro grau incompleto.

A maioria dos indivíduos falecidos era solteira, nascida na própria cidade de Campinas, na faixa etária de 20 a 29 anos de idade, morando na periferia, com pouca escolaridade e renda familiar inferior a dez salários mínimos - esta informação foi obtida para $68,0 \%$ dos casos. O número de pessoas que coabitavam a moradia do falecido variou de 0 a 17 , com média de 4,5 e mediana de 4 indivíduos. Em relação ao horário de ocorrência dos óbitos, houve uma concentração entre 20:00 e 01:00 (32,8\% dos casos), com um pico de ocorrência em torno das 20:00. Quase 50,0\% dos óbitos ocorreram em via pública.

Conforme ressalta a Tabela 1, a maioria dos óbitos analisados $(62,9 \%)$ referia-se a trabalhadores em atividade, isto é, indivíduos que no mês do óbito exerceram algum tipo de atividade remunerada.

Dentre estes trabalhadores em atividade analisados, $73 \%$ estavam inseridos no setor de serviços, trabalhando o restante na indústria, principalmente na construção civil. Com relação ao vínculo empregatício, apenas $30 \%$ tinham carteira de trabalho assinada no momento do óbito, conforme mostra a Tabela 2 .

Dentre os cem indivíduos analisados que trabalhavam à época do falecimento, 66 morreram vítimas de homicídio, 29 foram vítimas de acidentes e 5 suicidaram-se. Com base nas informações obtidas nas entrevistas realizadas, 27 destes óbitos foram caracterizados como decorrentes de acidente de trabalho, muito embora em nenhum caso o campo Acidente de Trabalho, situado na Parte V da DO, estivesse assinalado com “sim”. Dos 27 AT encontrados, 13 foram classificados como homicídios, 12 como acidentes de transporte e 2 como quedas acidentais. Desse modo, a mortalidade proporcional por acidentes de trabalho entre os trabalhadores masculinos falecidos por causas externas em Campinas foi estimada como 27,0\% (IC95\%: 19,6-34,4) no período estudado, sendo $100 \%$ o sub-registro da informação "acidentes do trabalho" na amostra estudada.

A Tabela 3 caracteriza os 27 óbitos classificados como acidentes do trabalho.

\section{Discussão}

Considerou-se que as perdas amostrais deste estudo tiveram interferência negligenciável nas estimativas obtidas, uma vez que, em sua maioria, distribuíram-se ao acaso (como é o ca- 
so das incorreções no campo endereço ou nas mudanças de endereço da família após o óbito), não implicando erros sistemáticos.

Dentre os óbitos amostrados e analisados neste estudo, 37,1\% ocorreram entre indivíduos que não exerciam trabalho remunerado há pelo menos um mês, e destes, um pouco menos da metade eram desempregados. Esta parcela da população estudada não estava exposta ao risco de morrer em decorrência de acidentes ocupacionais porque sequer conseguia se expor a agravos decorrentes do trabalho.

Conforme mostra a Tabela 2, dentre os trabalhadores ativos estudados, no mínimo 59,0\% trabalhavam no mercado informal da economia na ocasião do óbito. Importa notar a alta proporção deste seguimento na amostra estudada, quando comparada à proporção de trabalhadores informais em Campinas, que era cerca de 1/3 em 2000 18, sugerindo que a informalidade no trabalho é um fator de risco para óbito entre os trabalhadores, se não por uma maior exposição a riscos ocupacionais específicos (pois estes parecem ainda estar concentrados em setores tradicionalmente formais do mercado de trabalho, tais como a metalurgia, construção civil, transportes, indústria química, de alimentos, de papel etc.), mas talvez por uma maior vulnerabilidade do trabalhador informal, decorrente de seu desamparo jurídicoassistencial, seu menor poder aquisitivo e seu menor acesso a serviços de promoção e assistência à saúde. Some-se a isso uma maior exposição do trabalhador informal ao espaço de rua e ao contato direto com o público, aumentando o risco de acidentes de trânsito e violência em geral.

Conforme referido em Resultados, a mortalidade proporcional decorrente de acidentes do trabalho entre indivíduos ocupados do sexo masculino em Campinas no período estudado foi estimada em $27,0 \%$, isto é, cerca de um a cada quatro trabalhadores que morrem por causas externas em Campinas é vítima de acidente de trabalho fatal. Este resultado surpreende não apenas pela sua magnitude, mas especialmente por se tratarem todos eles de óbitos previsíveis e evitáveis, atingindo indivíduos jovens e produtivos. A análise das DO deste conjunto revela uma enorme omissão da informação sobre o vínculo com acidente de trabalho, confirmado nas entrevistas realizadas. Nenhuma destas DO trazia o campo Acidente de Trabalho assinalado com "sim". Potencializa a gravidade desta omissão o fato de a maioria destes indivíduos exercer trabalhos precários, sem carteira de trabalho assinada, situação que os colocam, de antemão, à margem das estatísticas do
Tabela 1

Distribuição da população estudada segundo a condição de atividade ao falecer. Campinas, São Paulo, Brasil, 1999/2000.

\begin{tabular}{lccc}
\hline Condição de atividade & $\begin{array}{c}\text { Freqüência } \\
\text { absoluta }\end{array}$ & $\begin{array}{c}\text { Freqüência } \\
\text { relativa (\%) }\end{array}$ & IC95\% \\
\hline Empregado & 100 & 62,9 & $57,2-68,6$ \\
Desempregado & 24 & 15,1 & $10,9-19,3$ \\
Em atividades ilícitas & 11 & 6,9 & $3,9-9,9$ \\
Inativo & 9 & 5,7 & $3,0-8,4$ \\
Estudante & 7 & 4,4 & $2,0-6,8$ \\
Estagiário & 1 & 0,6 & $0,0-1,5$ \\
Menor recluso & 1 & 0,6 & $0,0-1,5$ \\
Presidiário & 1 & 0,6 & $0,0-1,5$ \\
Informação ignorada & 5 & 3,1 & $1,1-5,1$ \\
Total & 159 & 100,0 & \\
\hline
\end{tabular}

Tabela 2

Distribuição da população estudada, empregada segundo vínculo empregatício ao falecer. Campinas, São Paulo, Brasil, 1999/2000.

\begin{tabular}{lccc}
\hline Posição na ocupação & $\begin{array}{c}\text { Freqüência } \\
\text { absoluta }\end{array}$ & $\begin{array}{c}\text { Freqüência } \\
\text { relativa (\%) }\end{array}$ & IC95\% \\
\hline Trabalhador formal & 30 & 30,0 & $22,4-37,6$ \\
Trabalhador informal & 24 & 24,0 & $16,9-31,1$ \\
Empregados sem carteira assinada & 4 & 4,0 & $0,7-7,3$ \\
Autônomos sem carteira assinada & 30 & 30,0 & $22,4-37,6$ \\
"Bico" & 1 & 1,0 & $0,0-2,7$ \\
Trabalhador não remunerado & 6 & 6,0 & $2,0-10,0$ \\
Empregador & 5 & 5,0 & $1,4-8,6$ \\
Ignorado & 100 & 100,0 & \\
Total & & & \\
\hline
\end{tabular}

maior banco de dados sobre acidentes do trabalho existente no Brasil: Sistema CAT. A exclusão deste contingente das estatísticas oficiais é mais uma das faces da exclusão social brasileira.

No Estado de São Paulo, ocorreram 25.644 óbitos masculinos por causas externas na faixa etária compreendida entre 15 e 64 anos no ano 2000 19. Se a estimativa obtida em Campinas (27/159) aplicar-se para todo o estado, estimase que desses óbitos, cerca de 4.355 deveramse a acidentes do trabalho, número seis vezes maior que o dado notificado pelo Departamento de Informática do SUS (DATASUS) em São Paulo em 2000, que foi de 722 óbitos, fato que nos permite estimar um sub-registro dos acidentes do trabalho fatais da ordem de $83,4 \%$. 
Óbitos relacionados ao trabalho, segundo a idade, a atividade exercida, classificação do acidente e a causa da morte. Campinas, São Paulo, Brasil, junho de 1999 a maio de 2000.

\begin{tabular}{|c|c|c|c|c|c|}
\hline n & $\begin{array}{l}\text { Idade } \\
\text { (em anos) }\end{array}$ & Atividade & $\begin{array}{l}\text { Classificação } \\
\text { do acidente }\end{array}$ & Causa do óbito & Observações \\
\hline 1 & 36 & Investigador da polícia civil & Típico & Homicídio por arma de fogo & Assassinado durante investigação policial. \\
\hline 2 & 40 & Pequeno comerciante & Típico & Homicídio por arma de fogo & $\begin{array}{l}\text { Trabalhava num bar de sua propriedade. } \\
\text { Assassinado durante o trabalho. (Assalto?) }\end{array}$ \\
\hline 3 & 29 & Pedreiro & Trajeto & Homicídio por arma de fogo & $\begin{array}{l}\text { Trabalhava por conta própria. } \\
\text { Assassinado na volta do almoço. (Assalto?) }\end{array}$ \\
\hline 4 & 31 & Balconista de lanchonete & Trajeto & Atropelamento; politraumatismo & $\begin{array}{l}\text { Acidente de transporte. Dirigia-se ao trabalho } \\
\text { em transporte público (perua): a porta se abriu } \\
\text { e ele caiu do veículo. }\end{array}$ \\
\hline 5 & 20 & Estoquista & Trajeto & $\begin{array}{l}\text { Colisão; traumatismo } \\
\text { crânio-encefálico }\end{array}$ & $\begin{array}{l}\text { Acidente de transporte. Dirigia-se ao } \\
\text { trabalho e bateu sua motocicleta na traseira } \\
\text { de um ônibus. }\end{array}$ \\
\hline 6 & 32 & Policial militar & Típico & Homicídio por arma de fogo & Assassinado durante investigação policial. \\
\hline 7 & 38 & Segurança particular & Trajeto & Colisão; politraumatismo & $\begin{array}{l}\text { Acidente de transporte. Voltava do trabalho: } \\
\text { seu carro capotou, batendo num caminhão. }\end{array}$ \\
\hline 8 & 38 & Escrivão da polícia civil & Trajeto & $\begin{array}{l}\text { Colisão e atropelamento; } \\
\text { traumatismo crânio-encefálico }\end{array}$ & $\begin{array}{l}\text { Voltava do trabalho, caiu de sua motocicleta } \\
\text { e foi atropelado. }\end{array}$ \\
\hline 9 & 33 & Motorista de caminhão & Trajeto & $\begin{array}{l}\text { Colisão; traumatismo } \\
\text { crânio-encefálico }\end{array}$ & $\begin{array}{l}\text { Voltava do trabalho. Bateu sua motocicleta } \\
\text { num caminhão. }\end{array}$ \\
\hline 10 & 46 & Pedreiro & Trajeto & Atropelamento; politraumatismo & $\begin{array}{l}\text { Voltava do trabalho e foi atropelado } \\
\text { numa rodovia. }\end{array}$ \\
\hline 11 & 31 & Operador de moto-serra & Trajeto & Colisão; politraumatismo & $\begin{array}{l}\text { Voltava do trabalho. Parou no acostamento } \\
\text { da estrada e sua motocicleta foi abalroada } \\
\text { por uma carreta. }\end{array}$ \\
\hline 12 & 43 & Pedreiro & Típico & $\begin{array}{l}\text { Queda; politraumatismo, } \\
\text { traumatismo crânio-encefálico }\end{array}$ & $\begin{array}{l}\text { Caiu durante trabalho de reparação } \\
\text { de rachaduras na parede de um prédio. }\end{array}$ \\
\hline 13 & 37 & Policial militar & Típico & $\begin{array}{l}\text { Homicídio por arma de fogo; } \\
\text { traumatismo crânio-encefálico }\end{array}$ & Assassinado durante investigação policial. \\
\hline 14 & 53 & Ajudante de serviços gerais & Trajeto & Homicídio por arma de fogo & $\begin{array}{l}\text { Assassinado quando dirigia-se para o trabalho } \\
\text { a pé. (Assalto?) }\end{array}$ \\
\hline 15 & 23 & Ajudante de cozinha & Trajeto & $\begin{array}{l}\text { Homicídio por arma branca; } \\
\text { lesão transfixante cardíaca } \\
\text { e hemorragia traumática aguda }\end{array}$ & $\begin{array}{l}\text { Discutiu com um colega de trabalho } \\
\text { e no retorno do trabalho foi assassinado. }\end{array}$ \\
\hline 16 & 34 & Carpinteiro & Típico & $\begin{array}{l}\text { Queda; traumatismo } \\
\text { crânio-encefálico e fratura } \\
\text { coluna torácica }\end{array}$ & $\begin{array}{l}\text { Estava fazendo um "bico" no fim de semana, } \\
\text { consertando a cobertura de um prédio. } \\
\text { A telha quebrou e ele caiu. }\end{array}$ \\
\hline 17 & 21 & Ajudante de mecânico & Típico & Homicídio por arma de fogo & $\begin{array}{l}\text { A oficina onde trabalhava foi invadida } \\
\text { por assaltantes que roubaram o local e o } \\
\text { assassinaram juntamente com o proprietário. }\end{array}$ \\
\hline 18 & 22 & Inspetor de seguros & Típico & $\begin{array}{l}\text { Colisão; traumatismo } \\
\text { crânio-encefálico }\end{array}$ & $\begin{array}{l}\text { Estava trabalhando e ao avançar um sinal, } \\
\text { sua motocicleta bateu num carro. }\end{array}$ \\
\hline
\end{tabular}

(continua) 


\begin{tabular}{|c|c|c|c|c|c|}
\hline $\mathbf{n}$ & $\begin{array}{l}\text { Idade } \\
\text { (em anos) }\end{array}$ & Atividade & $\begin{array}{l}\text { Classificação } \\
\text { do acidente }\end{array}$ & Causa do óbito & Observações \\
\hline 19 & 51 & Sócio de empresa médica & Trajeto & Atropelamento; politraumatismo & $\begin{array}{l}\text { Após o almoço foi ao banco e na saída foi } \\
\text { rendido por assaltantes que o seqüestraram. } \\
\text { Ao tentar fugir do carro em movimento } \\
\text { foi arrastado e atropelado. }\end{array}$ \\
\hline 20 & 29 & Pequeno comerciante & Típico & $\begin{array}{l}\text { Homicídio por arma de fogo; } \\
\text { traumatismo crânio-encefálico }\end{array}$ & $\begin{array}{l}\text { Trabalhava num bar de sua propriedade } \\
\text { e discutiu com um freguês que queria comprar } \\
\text { fiado. Foi assassinado. }\end{array}$ \\
\hline 21 & 28 & Motorista de táxi & Típico & $\begin{array}{l}\text { Homicídio por arma de fogo; } \\
\text { traumatismo crânio-encefálico }\end{array}$ & $\begin{array}{l}\text { Assalto seguido de morte. Trabalhava numa } \\
\text { cooperativa de táxi. }\end{array}$ \\
\hline 22 & 28 & Segurança privado & Típico & $\begin{array}{l}\text { Homicídio por arma de fogo; } \\
\text { perfuração da aorta por } \\
\text { instrumento perfuro-contundente }\end{array}$ & $\begin{array}{l}\text { Assassinado enquanto trabalhava como } \\
\text { segurança em baile. }\end{array}$ \\
\hline 23 & 43 & Vendedor de doces (camelô) & Trajeto & Homicídio por arma de fogo & $\begin{array}{l}\text { Havia ido ao banco para retirar dinheiro } \\
\text { para compra de mercadorias e foi assaltado. } \\
\text { Reagiu e foi assassinado. }\end{array}$ \\
\hline 24 & 26 & Frentista & Trajeto & Atropelamento; politraumatismo & $\begin{array}{l}\text { Estava retornando do trabalho por uma } \\
\text { rodovia e atropelou um homem que atravessava } \\
\text { a pista. Caiu da motocicleta e foi atropelado } \\
\text { por outro veículo. }\end{array}$ \\
\hline 25 & 34 & $\begin{array}{l}\text { Empilhadeirista } \\
\text { (metalúrgico) }\end{array}$ & Trajeto & Atropelamento; politraumatismo & $\begin{array}{l}\text { Voltava do trabalho. Aguardava no acostamento } \\
\text { de uma rodovia para fazer a travessia } \\
\text { em direção a sua casa e foi atropelado } \\
\text { por uma motocicleta. }\end{array}$ \\
\hline 26 & 27 & $\begin{array}{l}\text { Sócio de uma fábrica } \\
\text { de lajes }\end{array}$ & Típico & $\begin{array}{l}\text { Colisão; traumatismo } \\
\text { crânio-encefálico }\end{array}$ & $\begin{array}{l}\text { Saiu de motocicleta para medir uma laje e foi } \\
\text { atingido por um caminhão. }\end{array}$ \\
\hline 27 & 25 & Segurança privado & Típico & $\begin{array}{l}\text { Homicídio por arma de fogo; } \\
\text { traumatismo crânio-encefálico, } \\
\text { hemorragia traumática }\end{array}$ & $\begin{array}{l}\text { Trabalhava como vigia noturno de uma } \\
\text { empresa de transporte e turismo e foi } \\
\text { encontrado morto por colega de trabalho. }\end{array}$ \\
\hline
\end{tabular}

Lamentavelmente, conclui-se que nem mesmo um fenômeno tão contundente e explicitamente manifesto como a morte por acidente do trabalho consegue ser minimamente dimensionado pelas estatísticas oficiais brasileiras.

Analisando-se as características dos acidentes de trabalho encontrados, verifica-se que a violência urbana ganha relevância como fator desencadeante. Esta, além de ser a "causa básica" dos acidentes de trajeto (devido à chamada "violência do trânsito") e de alguns acidentes de trabalho típicos (tais como os dos vigias, seguranças privados e policiais civis e militares mortos em confrontos com assaltantes), passa agora a constituir uma nova categoria de acidentes de trabalho, que não apenas invade mais e mais os espaços laborais (como nos casos dos assaltos e homicídios que atingem o trabalhador no exercício de seu ofício), mas ocorrem no espaço da rua (como nos casos das balas per- didas, dos assaltos, dos estupros e outros tipos de violência que atingem o trabalhador no trajeto casa - trabalho). Nada sugere que seja esta uma situação particular de Campinas. Ao contrário, a percepção que se tem é que esse quadro seja encontrado, em maior ou menor amplitude, em todas as grandes cidades brasileiras.

Caso a legislação acidentária vigente fosse cumprida, do total de óbitos relacionados ao trabalho em Campinas aqui analisados, apenas 23,0\% (referentes a assalariados com carteira de trabalho assinada) teriam sido notificados como AT pelo Sistema CAT, o que infelizmente não ocorreu. No período estudado, não mais do que um AT fatal foi registrado pelo sistema de informação em saúde do trabalhador do município e nenhum foi corretamente caracterizado pela DO.

Há muito tempo discute-se sobre a necessidade de mudanças do sistema de notificação 
e registro de acidentes de trabalho e de integração entre os vários bancos de dados referentes aos agravos à saúde dos trabalhadores brasileiros. Todavia, a notificação e o efetivo controle dos acidentes do trabalho continuam sendo um grande desafio para o setor saúde. O sistema previdenciário deixa desamparada mais da metade da população economicamente ativa do país. Isto implica a urgente necessidade de redefinição da caracterização e reconhecimento legal dos acidentes do trabalho e também do aperfeiçoamento do sistema de informação existente de modo a contemplar todos os trabalhadores, oferecendo um diagnóstico mais aproximado da real ocorrência de AT no Brasil. Ao lado de antigos problemas, mudanças recentes e profundas no cenário sócio-econômico acarretaram grande transformação nas relações sociais e de trabalho. A crescente desregulamentação e precarização do trabalho, bem como o aumento do desemprego e da violência nos grandes centros urbanos do país impuseram significativas alterações no perfil de morbi-mortalidade dos trabalhadores brasileiros. Hoje, ações preventivas na área de saúde do trabalhador deverão necessariamente ultrapassar os limites do espaço da fábrica e contemplar essa nova realidade do mercado de trabalho. Assim fazendo, poderemos implantar medidas mais efetivas de prevenção e controle dos infortúnios laborais, começando a resgatar a dívida com os milhões de trabalhadores brasileiros que lutam diariamente pela sobrevivência, que contribuem com o seu trabalho para a produção e o desenvolvimento do país, cujos acidentes e óbitos nem ao menos são contabilizados pelos órgãos oficiais e cujas famílias, certamente, pouco podem desfrutar de amparo e solidariedade.
Resumo

Neste estudo epidemiológico foram analisados óbitos decorrentes de causas externas, ocorridos nos anos 1999 e 2000 entre moradores masculinos da Cidade de Campinas falecidos com idade entre 15 e 64 anos, por intermédio de entrevistas com familiares. Buscou-se correlacionar esta incidência com a história ocupacional dos indivíduos, permitindo a caracterização de tais eventos como acidentes de trabalho. A mortalidade proporcional devido a acidentes de trabalho foi estimada em 27,0\% neste grupo. Em nenhuma das Declarações de Óbito analisadas estava assinalado com "sim" o campo Acidente de Trabalho. Com base nos resultados, estimou-se que a informação oficial do Ministério do Trabalho e Emprego sobre o número de óbitos decorrentes de acidentes de trabalho no período no Estado de São Paulo esteja subestimada em 83,4\%. Constatou-se ainda que a imensa maioria dos acidentes de trabalho fatais identificados era de homicídios e acidentes de transporte, refletindo o aumento da violência nas grandes cidades brasileiras.

Acidente de Trabalho; Mortalidade; Violência

\section{Colaboradores}

Todos os autores participaram igualmente do planejamento do estudo, da coleta de dados em campo, da discussão e da redação do texto do artigo.

\section{Agradecimentos}

Pesquisa parcialmente financiada pelo FAEP/UNICAMP (Fundo de Auxílio ao Ensino e Pesquisa - Universidade Estadual de Campinas). 


\section{Referências}

1. Possas C. Avaliação da situação atual do sistema de informação sobre doenças e acidentes do trabalho no âmbito da Previdência Social brasileira e propostas para sua reformulação. Revista Brasileira de Saúde Ocupacional 1987; 15:43-67.

2. Alves S, Luchesi G. Acidentes do trabalho e doenças profissionais no Brasil: a precariedade das informações. Inf Epidemiol SUS 1992; 1:5-19.

3. Carmo JC, Almeida IM, Binder MCP, Settimi MM. Acidentes do trabalho. In: Mendes R, organizador. Patologia do trabalho. Rio de Janeiro: Ateneu; 1995. p. 431-55.

4. Lucca SR, Fávero M. Os acidentes do trabalho no Brasil - algumas implicações de ordem econômica, social e legal. Revista Brasileira de Saúde Ocupacional 1994; 22:7-14.

5. Hirata HS, Salerno MS. L'implantation d'outils statistiques sur l'organizasiotn et les conditions de travail dans les pays dits 'semi-développés' - Le cas du Brésil. In: Ministère du Travail, de l'Emploi et de la Formation Professionelle, éditeur. L'usage des méthodes statistiques dans l'étude du travail. Paris: Ministère du Travail, de l'Emploi et de la Formation Professionelle; 1995. p. 117-29.

6. Binder MCP, Cordeiro R. Sub-registro de acidentes do trabalho em Botucatu-SP. Rev Saúde Pública 2003: 37:409-16.

7. Fundação Instituto Brasileiro de Geografia e Estatística. Pesquisa Nacional por Amostra de Domicílios - 1999. http:/ /www.ibge.gov.br (acessado em 15/Abr/2003).

8. Ministério do Trabalho e Emprego. Indicadores de acidentes de trabalho. http://www.mtb.gov.br/ Temas/SegSau/estatisticas/acidentes/conteudo/ graficosindicadores.pdf (acessado em 15/Abr/ 2003).

9. Fundação Instituto Brasileiro de Geografia e Estatística. Tabela - População residente por sexo e situação do domicílio, população residente de 10 anos ou mais de idade, total, alfabetizada e taxa de alfabetização, segundo os municípios. http:// www.ibge.gov.br/home/estatistica/populacao/ce nso2000/ universo.php?tipo $=31 \& u f=35 \&$ letra $=C$ (acessado em 15/Abr/2003).
10. Secretaria Municipal de Saúde, Prefeitura Municipal de Campinas/Laboratório de Aplicação em Epidemiologia, Universidade Estadual de Campinas. Informe do projeto de monitorização dos óbitos no Município de Campinas: tendências da mortalidade por homicídios. Campinas: Secretaria Municipal de Saúde; 2001.

11. Reichenheim ME, Werneck GL. Anos potenciais de vida perdidos no Rio de Janeiro, 1990. As mortes violentas em questão. Cad Saúde Pública 1994; 10:188-98.

12. Cordeiro R, Donalisio MRC. Homicídios masculinos na região metropolitana de São Paulo entre 1979 e 1998: uma abordagem pictórica. Cad Saúde Pública 2001; 17:669-77.

13. Beraldo PSS, Medina MG, Borba EA, Silva LP. Mortalidade por acidentes de trabalho no Brasil uma análise das declarações de óbito, 1979-1988. Inf Epidemiol SUS 1993; 2:41-54.

14. Waldvogel BC. Acidentes do trabalho: os casos fatais - a questão da identificação e da mensuração [Tese de Doutorado]. São Paulo: Universidade de São Paulo; 1999.

15. Machado JMH, Gomez CM. Acidentes de trabalho: uma expressão da violência social. Cad Saúde Pública 1994; 10 Suppl 1:74-87.

16. Oliveira PAB, Mendes JM. Acidentes de trabalho: violência urbana e morte em Porto Alegre, Rio Grande do Sul, Brasil. Cad Saúde Pública 1997; 13:73-83.

17. Organização Mundial da Saúde. Classificação estatística internacional de doenças e problemas relacionados à saúde - 10a revisão. São Paulo: Edusp; 1993.

18. Pochmann M, Amorim R, organizadores. Atlas da exclusão social no Brasil. São Paulo: Cortez; 2003.

19. Departamento de Informática do SUS. Anuário Estatístico de Saúde do Brasil - 2001. http://tabnet. datasus.gov.br/cgi/deftohtm.exe?sim/cnv/obtsp. def (acessado em 01/Jul/2002).

Recebido em 04/Jun/2003

Versão final reapresentada em 06/Out/2003

Aprovado em 07/Nov/2003 